https://doi.org/10.7203/Normas.1.4647

\title{
LA NORMA LINGÜÍSTICA DEL ESPAÑOL DESDE UNA PERSPECTIVA LEXICOGRÁFICA: NORMA NACIONAL VERSUS NORMA PANHISPÁNICA
}

\author{
THE LINGUISTIC NORM IN SPANISH FROM A LEXICOGRAPHIC PERSPECTIVE: \\ NATIONAL NORM VERSUS PANHISPANIC NORM
}

\author{
Alejandro FAJARDO AGUIRRE \\ Universidad de La Laguna
}

\section{RESUMEN:}

La definición de la norma lingüística del español desde una perspectiva lexicográfica plantea dificultades y ha provocado debates intensos. Normalmente se otorga al Diccionario académico un valor normativo en el mundo de habla española, sin embargo no está concebido como estrictamente normativo, ya que da entrada a elementos diversos de carácter vulgar, jergal, etc. Por otra parte, ha sido rechazado como referencia normativa por quienes critican su centralismo o su falta de correspondencia con la situación real del español. Estas actitudes críticas se han expresado con frecuencia en la lexicografía hispanoamericana. Las Academias de la lengua española han dado pasos en los últimos años para configurar una norma de carácter panhispánico que sea alternativa real a la implantación de normas de ámbito local o nacional, pero en el terreno lexicográfico la tarea es ardua. Para llevarla a cabo es necesario fundamentar teóricamente con mayor profundidad el concepto de norma panhispánica y elaborar recursos lexicográficos útiles para adaptarla al español actual. La alternativa que se plantea es: avance en la configuración de una norma panhispánica o contienda entre normas nacionales.

PALABRAS CLAVE: norma lingüística, Lexicografía, diccionarios, americanismo, lengua española en América.

\section{ABSTRACT:}

The definition of linguistic norm in Spanish from a lexicographic perspective poses some problems and has led to heated debates. The academic Dictionary is usually given a normative value in the Spanish speaking community. However, it is not actually conceived as strictly normative as it includes entries of diverse nature such as vulgarisms, jargon, etc. On the other hand, those who criticize its linguistic centralism or lack of correspondence with the real situation of the Spanish language have rejected it as a normative reference. This criticism is more conspicuous in the Spanish-American lexicography. In the last few years, the Spanish language Academies have taken steps to create a norm with a panhispanic character as a real alternative to the establishment of national and local norms. However, it has turned to be a rather difficult task in the lexicographic field. To achieve this goal, it is necessary to provide a sounder theoretical foundation of the concept of panhispanic norm as well as useful 
lexicographic resources to adapt it to present-day Spanish. The alternatives are either progress towards a panhispanic norm or conflict between national norms.

KEY WORDS: linguistic norm, Lexicography, dictionaries, americanism, Spanish language in America.

\section{INTRODUCCIÓN}

Hablar de norma linguiística en el ámbito hispánico puede suscitar aún hoy día cierta incomodidad, resquemor o incluso resentimiento ante ciertos auditorios. No es una situación nueva, porque hay cuestiones sin resolver que permanecen enquistadas en discursos que se repiten periódicamente desde hace mucho tiempo.

El concepto de norma incluye habitualmente dos perspectivas: la norma en el sentido prescriptivo, o norma propiamente dicha, entendida como modelo que seguir, por una parte $\mathrm{y}$, por otra, la norma entendida como realización, como el producto lingüístico útil para comunicarse en un contexto sociolingüístico determinado, la norma como uso. La mayoría de los lingüistas ha reconocido esta ambivalencia del término y ha procurado referirse a ella utilizando diversas denominaciones ${ }^{1}$. Sin embargo, aunque la diferencia es muy fácil de discernir teóricamente, no se deja trasladar a la práctica lexicográfica. Es bien sabido que aunque se suele tomar el Diccionario de la Real Academia Española (DRAE) como referencia normativa del español, no registra solo lo que se debe decir, sino también muchas palabras de las que simplemente se dicen, aunque se consideren incorrectas, vulgares, locales, etc. Norma y uso se convierten en el diccionario en la pescadilla que se muerde la cola. El hablante necesita seguridad linguiística, busca dónde constatar la norma y presupone que encontrará en el diccionario una respuesta contundente y actualizada, espera de él la eficacia de la legislación y en cada nueva edición la contundencia de un real decreto. El consultor común del diccionario no busca medias tintas, sino respuestas inequívocas e ignora que en el DRAE faltan los neologismos más de moda y sobran los arcaísmos que deberían estar en un diccionario histórico que aún no existe. Espera de los académicos el papel de registradores de la propiedad léxica, pero en el diccionario encuentra un batiburrillo en el que caben los vulgarismos y adaptaciones de extranjerismos que le pueden resultar insólitas o risibles. No extraña, por tanto, que se haya convertido en un género la publicación en medios de comunicación -ahora también en la web colaborativa- de las reacciones del consultor del $D R A E$, que se muestra desencantado, frustrado o incluso afrentado ante la ausencia de algunas palabras o la presencia de otras en el «diccionario de la Academia».

${ }^{1}$ P. ej. norma - sistema (Coseriu 1952: 166-167), modelo - uso (Lara 1976: 12, 111), buen usouso habitual (Alvar 1982: 38), norma prescriptiva - norma descriptiva (Eberenz 1995: 50-51), etc. Más numerosas aun son las designaciones de la norma en el primer sentido, es decir, como modelo institucionalizado, así Kany (1969: 7) hablaba de: español consagrado, español culto, español estándar, español normal, español sancionado y español tipo.

NORMAS. REVISTA DE ESTUDIOS LINGÜÍSTICOS HISPÁNICOS, NÚMERO 1 (AÑO 2011):

https://www.uv.es/normas 
En la práctica, existen diferentes perspectivas entre lo que la lengua debe sersegún los criterios establecidos por una autoridad para algunos discutible- y lo que es en un ámbito social determinado, constituido muchas veces como país soberano. Esta circunstancia dio lugar en ocasiones a debates, proclamas y escarnios y tuvo su reflejo en los diccionarios, que pretendieron convertirse en no pocas ocasiones en instrumento reivindicativo de identidad y en muestra de prestigio nacional. Pero la preocupación por la disgregación de la lengua española -que también fue tópico tradicional y tema reiterado más desde la retórica que desde el análisis de datos- ha provocado que progresivamente se haya ido moldeando la idea de plasmar en forma de diccionario un modelo normativo válido por encima de las múltiples variedades del español. Este modelo, que aún tiene un perfil difuso, se ha dado en llamar norma panhispánica y está siendo impulsado en los últimos años desde la Asociación de Academias de la Lengua Española; la norma panhispánica debe aún ser definida teóricamente con mayor claridad y la elucidación del asunto requiere que se afronten cuestiones fundamentales aunque problemáticas, como es saber en qué medida el Diccionario académico, al que se otorga generalmente valor normativo en el mundo de habla española, puede seguir desempeñando ese papel con su configuración actual.

Las soluciones que en el futuro se ofrezcan al hablante que busque en el diccionario respuestas a sus dudas podrán darse de dos formas distintas, según la manera en que se vaya consolidando una u otra opción normativa: a) basándose en una norma panhispánica general, aún en gestación, apoyada en el consenso entre representantes del mundo hispánico (ciertamente representantes limitados al ámbito de las Academias) y b) mediante normas que se originan en el uso de territorios concretos, normalmente constituidos hoy como naciones, que expanden su variedad lingüística incluso a grupos supranacionales más amplios.

«Norma nacional versus norma panhispánica» es el subtítulo de este artículo, que hace un uso de la preposición latina deliberadamente polisémico, pues la interpretación etimológica del latinismo en el sentido de 'hacia' se contrapone con el valor que habitualmente se le da hoy como latinismo anglicado con el valor de 'contra', 'frente a'. Evolución desde la difusa situación actual hacia una norma hispánica aún por definir o contienda entre distintas normas nacionales que irradian su influencia: estas parecen ser las alternativas que se muestran en el horizonte ante la necesaria reconfiguración de la norma del español.

\section{LOS DEBATES EN TORNO A LA NORMA}

Sintetizando los diversos debates, proclamaciones y opiniones sobre la norma del español, destacamos los siguientes focos de interés:

a) Debate sobre la corrección en la que se dan interferencias entre los despectivamente llamados barbarismos y el uso normativo correcto; con frecuencia se asoció el mal uso con las variedades locales.

b) Debate sobre la supuesta preeminencia del español peninsular como referencia normativa para otras modalidades lingüísticas.

NORMAS. REVISTA DE ESTUDIOS LINGÜÍSTICOS HISPÁNICOS, NÚMERO 1 (AÑO 2011):

https://www.uv.es/normas 
c) Propuestas de normas de base nacional hispanoamericana como alternativa rupturista.

d) Competencia tácita entre diversos focos de una norma pluricéntrica que se postulan como modelo lingüístico para determinadas regiones hispanohablantes.

e) Reivindicación no rupturista de integración de usos locales o nacionales como parte de la norma.

f) Planteamientos integradores de panhispanismo lingüístico, en relación (no siempre fácilmente conjugable) con la idea del pluricentrismo.

Tras estos planteamientos, subyacen distintas ideas sobre el lenguaje, que en determinadas condiciones se plasman en ideologías lingüísticas, como plantea del Valle (2007: 20) (2010: 227-238), siguiendo Blommaert (2005:159). En este trabajo solo nos referiremos tangencialmente a las cuestiones de la norma relacionadas con la incorrección y nos centraremos en los problemas que plantea la definición de una norma hispánica (o panhispánica), frente a otras normas de carácter nacional o local ${ }^{2}$.

Como es sabido, es en el plano léxico donde con más intensidad se perciben las diferencias entre las variedades de la lengua usada en diferentes lugares, motivo por el que son muchísimas las opiniones al respecto que proceden de quienes tienen por oficio u ocupación la descripción del léxico. Por otra parte, el diccionario tiene un fuerte valor simbólico, desde antiguo ha sido usado para prestigiar la lengua y para ponerla al nivel de aquella que se considera modelo, ya sea la latina (esta era la intención de Covarrubias) ya sean de otras modernas con prestigio (el primer diccionario de la RAE pretendía poner al español en el XVIII a la altura de otras grandes lenguas como la francesa o la italiana que ya contaban con sendos diccionarios reputados). El hecho es que se consiguió hacer un gran diccionario (el Diccionario de Autoridades, que murió de éxito, pero tuvo pervivencia trasformado en el llamado «Diccionario usual») y se creó luego todo un linaje de diccionarios auspiciados por la Monarquía de España. Esta circunstancia contribuye a explicar las visiones contrapuestas sobre la valoración de la norma que desde España empezó a marcar el DRAE. La unión en el XVIII entre el poder político, representado por la monarquía de Felipe $\mathrm{V}$, y la institución creada para impulsar la normalización del español, a través de una academia real, no podía traer más que problemas de política lingüística en cuanto empezaron a surgir en América, tiempo después, las repúblicas independientes.

Casi trescientos años tras la creación de la institución que debía «limpiar fijar y dar esplendor» a la lengua, hay quien sigue viendo la influencia del poder español sobre la lengua con desconfianza y cierta hostilidad -a pesar de los cambios de imagen y de discurso experimentados últimamente con la propuesta de la «nueva política lingüística panhispánica» acordada con la Asociación de Academias de la Lengua Española

${ }^{2}$ El neologismo panhispánico, cuyo uso se ha difundido a raíz fundamentalmente del Diccionario panhispánico de dudas (2005) y, en menor medida, por alusiones diversas a partir de la divulgación de la política lingüística panhispánica de las Academias, puede utilizarse prescindiendo de la intensificación del prefijo, pues el adjetivo hispánico ya abarca por sí mismo al conjunto de los territorios y hablantes de español y establece oposición semántica con otras designaciones para lo local o lo nacional (no obstante, lo usamos en el título considerando la extensión de su en los últimos años). 
(AALE)-. Aún harán falta tiempo y esfuerzos mutuos para deshacer los resentimientos y prejuicios que se han acumulado en ambas orillas a lo largo de la historia común.

Una muestra de las divergentes visiones que han surgido a uno y otro lado del Atlántico la podemos ver en opiniones vertidas por lexicógrafos, filólogos, escritores, políticos y, en definitiva, por cualquiera que quisiera opinar, pues el debate se azuza fuera del ámbito lingüístico y se convierte fácilmente en tema enjundioso para animar tertulias. Valgan como muestra algunas citas:

- [...] que diez y ocho millones de españoles nos impongan la ley á cincuenta y tantos millones de americanos (Tobías Garzón 1910: V)

- Si hablar mal es una forma nacional de expresarse, hablemos mal (Rossi 1929: 0)

- Es injusto aplicar al habla de una comunidad un criterio de corrección exterior a ella (Rosenblat 1967: 7)

- Los peninsulares somos los amos de la lengua (Clarín, ap. Menéndez Pidal 1944: 32 y Rosenblat 1962: 53-54)

- ¡Qué vamos a ser los amos! (Menéndez Pidal 1944: 32)

- de cada diez hombres que hablan español por el mundo, sólo uno es de España (Alvar: 1991: 218).

Junto a actitudes lingüísticas de origen ideológico como las anteriores -ya rancias pero aún con arraigo emocional- en la actualidad se ha hecho presente con contundencia la idea de que la lengua es un recurso económico de primer orden. Estos planteamientos, que partieron del ámbito de la economía, fueron percibidos con claridad por los lingüistas más atentos a la evolución del español, como Lodares (2001: 173) (2005: 125). Si somos conscientes de que los diccionarios son el producto lingüístico que más sostenidos beneficios reporta a las empresas editoriales, podemos entender que el más o menos airado intercambio de ideas de otros tiempos resulte cándido hoy en día, cuando todo es cuantificable en cifras económicas.

\section{LA TOMA DE POSICIÓN DE LOS DICCIONARIOS ANTE LA NORMA HISPÁNICA}

En el debate sobre la norma lingüística, los diccionarios del español de América son un escaparate -o vidriera, si se prefiere- de las actitudes que se pueden adoptar al respecto, aunque los planteamientos que en ellos se hacen sean delicados de tratar, por afectar a los sentimientos nacionales y a la ideología. La lengua no es un simple «instrumento de comunicación»: puede servir además de instrumento de afirmación social, de prestigio personal, de opresión, de discriminación, de segregación, de creación de identidad nacional o de mercancía con la que comerciar. Como signos identitarios, los rasgos linguísticos que caracterizan a determinados grupos pueden ser objeto de prejuicios por parte de otras comunidades de hablantes; por consiguiente, el interés en lograr un reconocimiento normativo de peculiaridades locales es una preocupación constantemente manifestada en los diccionarios compuestos por quienes, por uno u otro motivo, consideran que su modalidad es injustamente valorada. Así, sentimientos e ideología pueden condicionar la redacción de los diccionarios y determinar su orientación, al perseguir objetivos extralexicográficos, bien pretendiendo 
convertirse en instrumentos que contribuyan a la afirmación nacional, bien mostrando disensión -aunque sea implícitamente- con la norma establecida fuera, en especial con la que se vincula a España. Cuando se busca resaltar la diferencia con respecto al uso de España, cabe el riesgo de crear con el diccionario un «efecto lupa», ya que se prestigia lo poco usual por el simple hecho de considerarse propio; esto puede llevar a confundir usos vulgares con usos propios, a incluir en el diccionario neologismos sin suficiente asentamiento y a confundir todo ello con usos engañosamente identitarios. En este sentido, puede darse en algún caso el interés por convertir en normativo un diccionario concebido en principio como descriptivo o diferencial, especialmente mediante su promoción como diccionario escolar. Quienes siguen viendo como una amenaza la «disgregación» del español, tal como la han planteado tradicionalmente polemistas diversos, podrían encontrar aquí nuevos motivos de alerta; para otros, en cambio, se trata simplemente de reequilibrar y prestigiar usos que consideran injustamente excluidos.

El debate crítico surgió en los prólogos de los diccionarios decimonónicos, donde se encuentran los primeros planteamientos que cuestionan cuál debe ser la norma a seguir, el papel de la variedad lingüística de España y su valor como modelo normativo. La lexicografía poscolonial hispanoamericana vino marcada por la reacción ante un sentimiento de inferioridad que se quería superar y un cuestionamiento, en consecuencia, de la supremacía normativa de España a través de la Real Academia, tal como se puede comprobar en el prólogo que escribe a su diccionario Uribe (1887: VIII):

El estudio y consideración de los americanismos sugiere tres preguntas, que en el fondo son una misma [...]. $1^{\circ}$ ¿Tienen derecho los americanos a ser admitidos en el Diccionario de la lengua, o deben ser proscritos y extirpados? $2^{\circ}$ ¿La lengua castellana está hoy en América en situación análoga a la del latín cuando empezaron a formarse los idiomas romances, o de otro modo: en las naciones hispano-americanas están formándose dialectos actualmente, y se debe fomentar como útil esa formación, u oponerse a ella como inconveniente? $3^{\circ}$ ¿Deben las naciones hispano-americanas reconocer y acatar la supremacía literaria de la Academia española?

La reacción anticasticista se extendió en los comienzos del s. XX, como vemos en Tobías Garzón (1910: V), quien se rebelaba ante la estrechez de la Real Academia Española a la hora de aceptar usos extendidos en América:

Veía en esto un desconocimiento de la ley ineludible y universal de la evolución de la lengua $[\ldots]$ pues equivalía á admitir [...] que diez y ocho millones de españoles nos impongan la ley á cincuenta y tantos millones de americanos.

Sin embargo, estas reacciones contra el casticismo venían a menudo lastradas por la permanencia de la idea de la corrupción del lenguaje, de manera que se daba una paradoja en la actitud de unos lexicógrafos que por una parte se reafirmaban como americanos, cuestionando una supremacía española que se extendía aún al dictado de la norma lingüística de la Academia, pero por otra parte iban a formar un frente común junto con la Española en la lucha contra los malos usos e influencias extranjeras, que

NORMAS. REVISTA DE ESTUDIOS LINGÜÍSTICOS HISPÁNICOS, NÚMERO 1 (AÑO 2011):

https://www.uv.es/normas 
muchos consideraban que afectaba especialmente a los americanos; algunos señalan también, no obstante, la corrupción en la lengua en España, como Ortúzar (1883: V):

Se nos tilda a los hispano-americanos de hablar cierta jerigonza y de ser como contrabandistas del idioma español: tantas son las locuciones vicios que tienden entre nosotros a convertirlo en un revuelto fárrago, ya que no en miserables dialectos. Gramáticos y literatos doctísimos han llamado la atención hacia esta corruptela que aflige también a la nuestros hermanos peninsulares.

Este enfoque purista se prolongó mucho tiempo y no se superó hasta las últimas décadas del s. XX (Haensch 1997: 225), cuando liberados los diccionarios por fin de la crítica de barbarismos, solecismos, etc., quedó el interés por el léxico más cercano, el de la propia región o del país, lo que dio lugar a un gran número de nuevos diccionarios que abrieron la etapa de la lexicografía regional y nacional (Fajardo 2010: 37-38).

Lo habitual ha sido que sobre una base importante de estas obras de enfoque local, muchas de ellas pertenecientes a la anterior etapa, se hayan terminado redactando diccionarios nacionales, que han cribado los datos anteriores y, con uno u otro método, los han contrastado con el uso coetáneo. Salvo en los pocos casos de diccionarios nacionales elaborados con un criterio descriptivo o integral, el resto tiene su punto de mira enfocado a España para establecer lo que le es propio por comparación con los usos de la Península Ibérica; de ahí que algunos hayan tildado de «eurocéntricos» a los diccionarios diferenciales de esta etapa, como Zimmermann (2003: 71-83) quien critica que la lexicografía diferencial americana pretenda valorar y reivindicar lo propio sin ser capaz de desligarse de la referencia constante al uso de España.

Dentro de este primer grupo, el de los denominados diccionarios diferenciales, unos recogen el léxico nacional por oposición al «español general»; así hace Tejera (1983) y el $D A(2010)$ :

Como norma fundamental para la selección de las unidades léxicas se ha seguido el criterio de contrastividad frente al castellano general. El español general no pertenece a ninguna región específica de España ni de América; se le considera como una entidad no establecida, pero perceptible -especie de koiné- en la que se expresan y comprenden las personas cultas de habla hispana. (Tejera 1983: XVII).

Otros concretan de forma inequívoca el léxico con el que se comparan, tomando como referencia generalmente el registrado en el DRAE, como hizo Félix Morales (1987) con la primera versión del Diccionario ejemplificado de chilenismos. Sin embargo, la dependencia del $D R A E$ ha creado un problema generalizado, porque numerosos diccionarios han tomado por usos americanos muchísimas palabras usuales en España, pero que no estaban registradas en el DRAE (por emplearse en un registro coloquial, ser voces regionales, neologismos, vulgarismos, etc.). Otros han hecho algo similar con Moliner (1966 y 1998) como Quesada (1993) en el Nuevo diccionario de costarriqueñismos y los hay que comparan el léxico nacional con la variedad del español usado con mayor frecuencia en la zona central de la Península Ibérica, como p. ej. Haensch/Werner (1993 a, b, c y 2000): 
Según el criterio diferencial, sólo se registran en el Diccionario del español de Argentina unidades léxicas del español argentino que presentan en su uso actual algún rasgo diferenciador con respecto al español peninsular. (Haensch/Werner 2000: XX).

En su perspectiva de contraste, estos diccionarios evitan el problema de las coincidencias con Canarias -que se muestra en el Tesoro léxico canario-americano de Corrales y Corbella (2010)- hablando de español peninsular; sin embargo, la denominación sigue resultando inadecuada, pues la diferencia la establecen en realidad con el español centro-peninsular, al no considerar las coincidencias que hay por razones históricas entre determinados países americanos y regiones peninsulares como Andalucía, Extremadura, León, Asturias, Galicia, etc. El punto de enfoque de la contrastividad entre variedades léxicas del español muestra, por otra parte, un desequilibrio, ya que opone unidades políticas de América (países completos) con partes de un país, España, del que quedan fuera las variedades léxicas del español meridional y de otras zonas, periféricas geográficamente, pero no lingüísticamente.

Los diccionarios de americanismos siempre adoptan, explícitamente o no, una posición ante el problemático concepto de español peninsular o español de España y para evitar complicaciones metodológicas, suelen ignorar la existencia de variedades regionales en España (especialmente las de Andalucía y Canarias) que en ocasiones son el origen del uso americano. La opción alternativa sería reflejar el uso de determinado país o región al completo, (la lexicografía integral) pero esta es muy costosa, porque es grande la inversión de tiempo y esfuerzo que se necesita para obtener resultados que puedan aportar una mejora respecto a los diccionarios ya existentes. Los autores de uno de ellos, el Diccionario del español usual en México, son conscientes de que el corpus que sirve de fundamento para el diccionario se queda corto para reflejar la variedad léxica interna del país (Lara: 1996):

Debido a las características de nuestra investigación, determinadas por el costo que significaría efectuar una gran encuesta léxica nacional, los datos que registramos no dan cuenta debida de esa variedad, por lo que el vocabulario regional que se encuentra en estas páginas apenas representa un pequeño porcentaje de lo que realmente se habla en nuestro territorio $[\ldots]$ Les pedimos por ello a nuestros lectores que sean benevolentes con nosotros en este aspecto [...].

Los diccionarios integrales (o descriptivos) no comparan las palabras unidad a unidad con una referencia externa, sino que se limitan a registrar un conjunto léxico usual en su ámbito nacional; por tanto, su objetivo en el caso de los americanos no es reunir americanismos, a diferencia de los de tipo diferencial (vid. supra), sino poner en valor una variedad de la lengua que busca su definición dentro de unos límites constreñidos políticamente a las fronteras nacionales:

Lo que queremos, [...] es devolver a los hispanohablantes mexicanos el vocabulario de su propia lengua, tal como se usa, para que en Europa, lo conozcan y aprecien mejor. En cuanto a la gran comunidad hispanohablante, en América, Europa,

NORMAS. REVISTA DE ESTUDIOS LINGÜÍSTICOS HISPÁNICOS, NÚMERO 1 (AÑO 2011):

https://www.uv.es/normas 
Asia y África, lo que le ofrece el $D E M$ es un vocabulario de uso mexicano que hace evidente la unidad de la lengua por la que tanto nos hemos esforzado desde la época de nuestras independencia, a la vez que muestra la riqueza derivada de un español arraigado en la experiencia histórica de México, seguramente semejante a la variedad que se encuentra en los otros veintiún países que forman la comunidad hispánica, y que históricamente ha sido soslayada por el centralismo académico y la idea de la lengua a la que ha dado lugar. (Lara 2010: 27).

El resultado de la compilación del léxico que hacen estos diccionarios descriptivos da la impresión de que no se diferencia en una cuantía excesivamente grande respecto al español general y también parece que la base léxica no marcada presenta un alto índice de coincidencia entre diversas variedades del español (apreciaciones subjetivas que precisan ser constatadas con estudios cuantitativos). En cualquier caso, la diferenciación es sin duda menor de lo que podrían sugerir los compendios de los diccionarios diferenciales.

El primer diccionario descriptivo del español, el Diccionario del español actual (DEA) (Seco: 1999) es sin duda el más completo de los publicados en el ámbito hispano hasta la fecha, está basado en las palabras «usadas por los españoles» (Seco 1999: XIII) documentadas de 1955 a 1993, reúne unas 75000 entradas y es el único que aporta exhaustivamente citas, renunciando a los habituales ejemplos sin paternidad constatable de otras obras. Sin embargo, resulta chocante -también en la acepciones americanas de la palabra (DRAE 2001 s. v. chocante)- que años después de su publicación no sea tenido en cuenta por quienes anacrónicamente siguen afirmando que «el predominio ideológico y prescriptivo de la Academia logró que cualquier otro diccionario integral del español no fuera sino una refundición del académico, con algunos retoques» (Lara 2010: 18).

El $D E A$ es un diccionario hecho con reflexión sobre sus propios límites. La ambición de sus autores se ha orientado a refinar una técnica lexicográfica cuyo resultado se muestra impecable. Se define como un diccionario descriptivo, sin más intención normativa que la que es inherente a cualquier diccionario:

Es un diccionario descriptivo, no normativo. Esto no quiere decir que se abandone sin más una de sus funciones -la orientación idiomática- que siempre han asignado los hablantes a esta clase de obras. En realidad, ambos enfoques, descriptivo y normativo, no son incompatibles (Seco 1999: XIII)

La orientación metodológica descriptiva ha dado lugar en México al Diccionario del español de México (DEM), dirigido por Lara (2010) que se basa un corpus de textos de este país, fundamentalmente de la época de 1921 a 1974 (Lara 2010: 20). Reúne unos 25000 vocablos. El diccionario, cuya concepción se fraguó en los años setenta del pasado siglo, fue víctima - como otros proyectos de los setenta y los ochenta- de la revolución informática que obligó a pasar de las papeletas a los archivos digitales cuando su confección era aún un trabajo tedioso, lento y costoso. Los años invertidos en la experimentación computacional con tarjetas perforadas, que pocos años después nos resulta tan rudimentaria, fueron en detrimento de la producción lexicográfica, que 
pretendió justificarse con la publicación de breves diccionarios de compromiso que desvirtuaron el enfoque descriptivo original y fueron adaptados para presentarse como de utilidad para el uso escolar (Fajardo 2010: 339). Por otra parte, cabe preguntarse por la validez del corpus en que se basa el diccionario -correspondiente a las décadas centrales del pasado siglo- para presentarse como útil para describir el uso actual del español en México.

Inspirado en el modelo de Lara, el Diccionario integral del español de la Argentina (DIEA) (Plager: 2008) parte de un corpus de textos argentinos publicados a partir de 1981, este sí rápidamente procesado, etiquetado y lematizado sin las fatigas de los mexicanos. Sin embargo, al igual que el diccionario mexicano, tampoco pudo mantener la «pureza» con la que surgió del corpus y debió recurrir a otros recursos para ser completado: diccionarios de argentinismos, diccionarios generales, glosarios etc., con lo que las 15000 palabras que se obtuvieron del corpus se convirtieron de esta forma en el diccionario en 40000 (Plager 2008: 12).

Es evidente que con ampliaciones y manipulaciones como estas, ni el DIEA ni el $D E M$ se pueden considerar diccionarios descriptivos en sentido estricto, porque los corpus informatizados de los que parten sufren luego adaptaciones y ampliaciones más artesanales que los invalidan metodológica y tipológicamente como descriptivos.

Algunos han podido ver en el DEM (2010) una intención normativa nacional. Los recelos se pueden comprender tras comprobar las limitaciones del diccionario para poder ser considerado estrictamente descriptivo y teniendo en cuenta que el director de la obra se ocupó de los aspectos teóricos de la norma lingüística y se ha mostrado más alineado con la idea de la construcción de una norma nacional que con propuestas panhispánicas (Lara: 1976, 2007). En la misma narración que se hace en el prólogo sobre la concepción del diccionario se cuenta cómo por iniciativa de cierto político se propuso a El Colegio de México hacer un «Webster mexicano» para orgullo patrio. Cuando el devoto erudito de Connecticut Noah Webster publicó en 1828 su An American Dictionary of the English Language, daban su fruto los grandes proyectos lexicográficos gestados en decenios anteriores y disfrutaban de libertad los nuevos estados como México, pero emular concepciones lexicográficas del s. XVIII dos siglos más tarde es, evidentemente, una ocurrencia con un origen más político que lingüístico. En cualquier caso, en el prólogo del DEM se pretende neutralizar los resquemores que la publicación pudiera causar entre quienes ven en ella un nuevo peligro de fractura de la norma del español. Es cierto que en su prólogo se alude a la independencia nacional, se critica el centralismo académico y se dirige a Europa «para que lo conozcan y aprecien mejor», en referencia al español de México (vid. supra). Pero al mismo tiempo muestra una actitud conciliadora, pues si bien por una parte afirmaba que pretende «devolver a los hispanohablantes mexicanos el vocabulario de su propia lengua»-como si no fueran los dueños de ella- por otra parte se repite el tópico de la adhesión a la deseada unidad de la lengua española.

Lo que nosotros queríamos era un diccionario integral del español, basado en el uso mexicano. No, como lo publicó alarmado el ABC de Madrid, para "dar nuestro grito de independencia", ahora lingüística, y producir un "cisma de la lengua española", sino para

NORMAS. REVISTA DE ESTUDIOS LINGÜÍSTICOS HISPÁNICOS, NÚMERO 1 (AÑO 2011): https://www.uv.es/normas 
corresponder a una lengua que, en México, está en el origen de nuestra nacionalidad y de nuestra cultura, sin negar la siempre deseada unidad del español y también sin menoscabar la rica actualidad de las lenguas indígenas. (Lara 2010: 18)

Sin embargo, al margen de declaraciones más o menos biensonantes, la cuestión decisiva es el uso que se pretenda llegar a dar a este tipo de diccionarios: ¿se trata de obras descriptivas o tienen finalidad normativa? En caso de extenderse su utilización en una enseñanza obligatoria orientada a estandarizar una norma nacional ¿se podría mantener que son una contribución al mantenimiento de la unidad de la lengua? Cuando se critica el carácter «centralista» de los diccionarios académicos (rasgo más propio de otras épocas que de la tendencia integradora de los últimos tiempos) ¿es conveniente pretender sustituirlos por otros diccionarios centrados exclusivamente en unos límites políticos nacionales? Las respuestas deben ser dos, pues dos son los polos entre los que oscila la declaración de intenciones de estos diccionarios que se mueven en un margen de cierta ambigüedad entre la reivindicación nacionalista y las loas a la unidad del español. Si los diccionarios se plantean como descriptivos, sin pretender erigirse en referencia normativa, son una interesante contribución para el conocimiento del uso léxico del español dentro de unos límites fronterizos muy extensos. Si, por el contrario, aspiran a convertirse en referencia normativa para su país, están sustituyendo un mal (unos diccionarios, los académicos, que por carencias históricas y metodológicas infrarrepresentaban a determinadas variedades del español) con otro mal mayor: unos diccionarios que ignoran a las variedades que no se hablen dentro de sus fronteras nacionales.

Es difícil que un diccionario se postule seriamente como una contribución sustancial para que se consolide la norma nacional respecto al resto de los hablantes externos a ella y que para guiarla logre sustituir a otros diccionarios de orientación más panhispánica, presentándolos como ajenos, porque con ello se mostraría una actitud anacrónica y abocada al fracaso por ser extraña a la globalización general, también idiomática, que vivimos. En cualquier caso, de una cosa podemos estar seguros para decepción de lexicógrafos: ningún diccionario va a provocar en el mundo actual un «cisma de la lengua española».

Un buen diccionario no es necesariamente un producto del nacionalismo, ni el hecho de haber sido compuesto «en casa» conlleva una garantía de éxito; se debe competir en calidad y conseguirla es una tarea difícil, pues incluso editoriales con tradición y fuerza empresarial se resienten ante la potencia y difusión de la oferta académica.

Pero por otra parte, también es necesario mostrar cautelas ante el tradicional otorgamiento del valor normativo a los diccionarios académicos, porque cuentan con un prestigio heredado que se ha visto reforzado gracias a una creciente orientación panhispánica; su modernización, su red internacional y los recursos a los que tienen acceso, puede abocar a que la lexicografía académica monopolice algunos ámbitos de la lexicografía del español.

Aunque la producción académica sea la referencia de la norma hispánica, ofrezca calidad creciente y goce de difusión, el mantenimiento de la diversidad del trabajo 
lexicográfico en ámbitos diferentes, fundamentalmente en aquellos que tienen relación con la investigación en el ámbito universitario, son a largo plazo una garantía de la mejora constante a la que debe aspirar la Lexicografía como disciplina científica.

\section{AVANCES EN LA CONFIGURACIÓN DE UNA NORMA PANHISPÁNICA}

Una contribución fundamental para el avance en la definición de una norma lingüística hispánica es el Diccionario de americanismos (DA) dirigido por López Morales (2010). En la «guía del consultor», que precede al diccionario, se lo caracteriza como «dialectal, diferencial, descriptivo, usual, descodificador y actual». No es un diccionario normativo (en sentido prescriptivo) del español, pero el hecho de haberse convertido en el diccionario de americanismos del español por antonomasia le otorga un poder de referencia que indudablemente tendrá consecuencias en la configuración normativa de nuestra lengua: documenta usos y con ellos realiza una selección, fija significados con definiciones eficaces, adscribe las voces a niveles socioculturales o a grupos sociales determinados, localiza su extensión geográfica... ¿No son estas tareas propias de una obra lexicográfica de carácter fundacional? Una obra descriptiva como esta, aunque se describa como un diccionario que no es normativo, puede tener sin duda un efecto normativo y contribuir al conocimiento de la diversidad y extensión de las voces, datos básicos a la hora de comenzar a definir el inventario léxico que guíe la norma hispánica.

El límite de lo dialectal a que se atiene el Diccionario de americanismos responde a un criterio puramente geográfico, no es un diccionario de dialectalismos de la lengua española, sino de la lengua española en América; cierto es que al no pretender establecer, como indica en la introducción, una comparación con el español de España, sino con el español general, no existiría impedimento metodológico para que se hubiera hecho un diccionario general de dialectalismos del español, reconociendo la igualdad entre las distintas zonas hispanohablantes e introduciendo definitivamente la marca de España o de sus zonas dialectales en la localización geográfica de las voces. ¿Qué impide dar entrada a andalucismos o incluso a madrileñismos (ahora que también tenemos un excelente nuevo diccionario diferencial, el Diccionario de madrileñismos? (DM) (Alvar Ezquerra: 2011).

Los datos aportados por el $D M$ serán fundamentales para conocer -y en su caso corregir- el peso que en el $D R A E$ se da al léxico propio de Madrid. Se encontrarán, sin duda, palabras que siendo de uso exclusivamente madrileño aparecen sin marca en el Diccionario académico, atribuyéndoles un falso uso general. Recurrentemente se han formulado críticas contra la RAE por este hecho, aportando como único argumento algunos ejemplos; ahora, sin embargo, lo que se proporcionan son datos para actuar en consecuencia. Se podrán localizar geográficamente con la marca Madrid algunos falsos generalismos del DRAE, pero también se podrá comprobar la abundancia de léxico diferencial madrileño no recogido ni en esta ni en otras obras lexicográficas. Por otra 
parte, el $D M$ aporta elementos para reflexionar sobre qué entienden por 'Madrid' quienes afirman que la norma que marca el $D R A E$ se basa en el uso madrileño.

Comparando todos los diccionarios diferenciales del español de distintas zonas, llegamos a la conclusión de que la creación de diccionarios de americanismos responde a criterios que se basan en la tradición, en el sentido práctico, o en la simplificación de una visión bipolar del español (español de España frente a español de América), pero no en criterios exclusivamente lingüísticos, porque dar entrada, p. ej., a cubanismos y dejar fuera a los canarismos puede servir para reducir el volumen de la obra, o para enmarcarla dentro de la tradición lexicográfica que consiste en hacer diccionarios de americanismos, no de dialectalismos generales del español), pero no a criterios metodológicos: es difícil encontrar una justificación lingüística desde el momento en que se renuncia a hacer la contrastividad del léxico con España y se hace con el español general. En cualquier caso, estamos ante un diccionario de americanismos -el mejor sin duda- y ese es su límite. Su presencia, por contraste, recuerda una vez más la inexistencia de un correlato en forma de diccionario de regionalismos o de españolismos que se ocupe de todas las regiones de España y que tenga un carácter contrastivo respecto al español común, tarea compleja que deberá esperar a que se siga trabajando en las distintas comunidades, tal como se ha hecho con éxito en Canarias, Madrid, etc. Por tanto, para la definición de un inventario léxico que pueda constituirse en base de la norma hispánica, sigue siendo una tarea necesaria unir estos datos del Diccionario de americanismos a la enorme riqueza del léxico regional de España, tratarlos con el mismo método y darles a todos ellos el peso que cuantitiva $\mathrm{y}$ cualitativamente les corresponde.

La explicación de esta aparente contradicción del $D A$ en cuanto a la referencia con la que busca establecer la diferencia es probable que se deba buscar en el cambio conceptual que se constata a lo largo de su elaboración: cuando se publicó en 2003 una síntesis de su planta se afirmaba: «es un diccionario dialectal -del español de Américay diferencial con respecto al español de España». (López Morales 2003: 115). Posiblemente el impulso de la llamada política lingüística panhispánica, que cobró fuerza públicamente a partir de 2004, propició que se pasara a hablar de un español general, lo que se refleja en el cambio conceptual posterior, pues según se indica en 2010 (DA: XXXI) (la cursiva es nuestra):

El Diccionario de americanismos es diferencial con respecto al español general. En el plano léxico se entiende por «español general» el conjunto de términos comunes a todos los hispanohablantes (sol, cama, agua, comer...) -bastante más del 80 por ciento de nuestro vocabulario-, independientemente de la variedad dialectal particular que se maneje. No se trata, pues, de establecer la contrastividad con el «español de España» como ha sido habitual hasta ahora.

Por otra parte, el $D A$ es un diccionario «descriptivo» y registra el uso real sin atender a lo que la norma recomiende por lo que da cabida a todo tipo de términos malsonantes, tabuizados, vulgares, extranjerismos, neologismos, etc. Las formas documentadas tienen prioridad sobre las consideradas correctas, de manera que si la 
palabra está documentada solo en una forma, aparecerá así aunque vaya en contra de las normas ortográficas, puesto que el diccionario «no es normativo».

Sin embargo, ya hemos señalado lo que es bien sabido: el diccionario per se contribuye a la fijación y difusión de formas por el simple hecho de registrarlas, si una forma documentada tiene prioridad sobre la forma correcta, se está dando el primer paso para su generalización, ya que cualquier forma documentada prevalece sobre la supuestamente correcta pero no documentada, como se demuestra desde las primeras documentaciones históricas de la lengua.

\section{CONCLUSIONES}

Durante mucho tiempo, en el ámbito de la lexicografía no se han experimentado avances significativos en un diálogo fructífero para la configuración de una norma aceptada por consenso, lo habitual han sido las especulaciones y las tópicas declaraciones retóricas sobre las bondades de la unidad de la lengua, mientras que las críticas, argumentadas o airadas, referidas a la norma dictada por la Academia muy pocas veces fueron tenidas en cuenta.

En las últimas ediciones del Diccionario, la Academia ha avanzado de manera positiva, aunque con lentitud y sin abordar los problemas de fondo: se ha dedicado sobre todo a ir aumentando cuantiosamente, pero de manera asistemática, el número de voces con marcas geográficas americanas. Mientras tanto, la reacción de quienes se han sentido desatendidos por los encargados de definir la norma común ha producido en los últimos años algunas obras que se pueden valorar positivamente por su aporte de nuevos datos para el conocimiento de la realidad del léxico español en determinadas regiones, pero su uso como alternativa normativa nacional difícilmente llegaría a tener éxito, caso de plantearse, pues al prestigio de la lexicografía académica y a la progresiva mejora de su calidad se suma su influencia global y la accesibilidad gratuita a través de Internet.

Pero esta posición de absoluta preeminencia que mantiene la lexicografía académica, no debería impedir que estas instituciones linguiísticas se adapten, no solo técnicamente, a la realidad actual del español. Para lograrlo, es necesario replantearse hasta cuándo puede el Diccionario académico seguir siendo un modelo normativo válido, con su viejo esqueleto ya veintidós veces remozado.

La constancia en el trabajo común en la Asociación de Academias de la Lengua Española puede hacer avanzar la configuración de una norma hispánica aceptable para todos con mayor o menor dificultad, pero sin reticencias y resquemores que deberían ser superados. La publicación del $D A$ es trascendental, porque su enfoque novedoso debería obligar a la lexicografía académica a profundizar en la política lingüística panhispánica y a redefinir la norma léxica del español actual. El uso de la lengua solo puede ser pluricentrista, es decir, reflejar la variación real existente, pero la norma prescriptiva necesita para ser eficaz una referencia unívoca que sin rechazar unos usos locales ni priorizar otros (tampoco el de España) difunda los mayoritarios y consensuados como una referencia normativa. Para ello, sigue siendo necesario describir los usos peculiares y la lexicografía diferencial tiene aún tarea por delante, aunque el trabajo realizado para 
el $D A$ será sin duda una base sólida para su desarrollo en los próximos años. Por otra parte, la lexicografía integral tiene su propio campo de trabajo para ayudar a conocer el uso real de las regiones, siempre que se base en corpus reales sin manipular, pero para ser creíble no puede venderse sin más como escolar, atendiendo a intereses comerciales o prácticos, porque los diccionarios necesitan para cumplir esta función una reelaboración del corpus base que los invalida científicamente como diccionarios descriptivos.

No hay que olvidar que, mientras la redefinición de la norma toma cuerpo en una nueva forma lexicográfica, los hablantes buscarán en el diccionario una referencia necesaria de autoridad. Si la vieja norma no es sustituida por una alternativa convincente y aceptada, se facilitará la extensión de los usos divergentes, es decir, de las norma nacionales, que tenderán a consolidarse a costa de ir borrando las variedades menos potentes dentro de su ámbito de influencia regional. No hay una norma pluricéntrica, sino distintas normas nacionales, el uso sí es pluricéntrico, pero la norma que aspire a cumplir una función válida para todos debe ser unívoca, no focalizada y supranacional. La alternativa «norma nacional versus norma panhispánica» se debería plantear como una construcción de la norma desde las variantes nacionales hacia la norma panhispánica, no como una contienda de unas normas contra otras, etapa que debería ser definitivamente superada. Desde la perspectiva lexicográfica, en los próximos años comprobaremos en qué medida la norma lingüística panhispánica se concreta en nuevas obras aceptadas como referencia o se queda en un compromiso utópico.

Mientras tanto, las reflexiones de Julián Marías al respecto nos recuerdan lo sutil de la frontera entre el uso y la norma y la facilidad con que una cosa puede trasformarse en la otra:

Lo decisivo es el uso, no la vieja norma purista, pero cuando se ha dicho esto, que es verdad, se cae en la cuenta de que el uso es normativo (Marías 2000: 293)

\section{REFERENCIAS BIBLIOGRÁFICAS}

AlEZA IZQUIERDO, Milagros, coord. ${ }^{\mathrm{a}}$ (2011): Normas y usos correctos en el español actual, Valencia, Tirant Humanidades.

Alvar EZQuerra, Manuel (2011): Diccionario de madrileñismos: voces patrimoniales y populares de la comunidad de Madrid, Madrid, Ediciones La Librería.

Alvar LóPEZ, Manuel (1982): Lengua, libertad y otros estudios, Madrid, Ed. Cultura Hispánica - Instituto de Cooperación Iberoamericana.

Alvar LóPEZ, Manuel (1991): El español de las dos orillas, Madrid, Mapfre.

Asociación de ACAdEMias de la Lengua EsPañola, (2010): Diccionario de americanismos, Santillana. 
Blommaert, Jan (2005): Discourse: A Critical introduction, Cambridge University Press.

Corrales, Cristóbal y Dolores Corbella (2010): Tesoro léxico canarioamericano, Las Palmas de Gran Canaria, Cabildo de Gran Canaria.

COSERIU, Eugenio (1952): Sistema, norma y habla, Montevideo, Universidad de la República.

EBERENZ, Rolf (1995): «Norm und regionale Standards des Spanischen in Europa und Amerika», en Müller O. et al. (eds.), Gegenwärtigen europäischen Sprachen. Beiträge zur gleichnamigen Fachkonferenz, November 1994, Universität Rostock, $47-$ 58.

FAJARdo AguirRe, Alejandro (2010): «La lexicografía del español de América: evolución, tipología y metodologías», en Milagros Aleza Izquierdo y José María Enguita Utrilla, coords., La lengua española en América: normas y usos actuales, Valencia, Universitat de València. Con la colaboración de Marta Albelda Marco, Antonio Briz Gómez, Miguel Calderón Campos, Eduardo España Palop, Alejandro Fajardo Aguirre, Félix Fernández de Castro, David Giménez Folqués, Rosario Navarro Gala y Antonio Torres Torres, 317-354. Publicación en línea: <http://www.uv.es/aleza/esp.am.pdf>.

GARZÓN, Tobías (1910): Diccionario argentino: Ilustrado con numerosos textos, Barcelona, Imprenta Elzeviriana.

HAENSCH, Günther (1997): Los diccionarios del español en el umbral del siglo XXI, Salamanca, Ediciones Universidad de Salamanca.

HAENSCH, Günther y Reinhold WeRnER, dirs. (1993): Nuevo Diccionario de Americanismos. Tomo I Nuevo Diccionario de Colombianismos, Bogotá, Instituto Caro y Cuervo.

HAENSCH, Günther y Reinhold WeRnER, dirs. (1993): Nuevo Diccionario de Americanismos. Tomo II. Nuevo Diccionario de Argentinismos, Bogotá, Instituto Caro y Cuervo. Coordinadores: Claudio Chuchuy y Laura Hlavacka de Bouzo.

HAENSCH, Günther y Reinhold WERNER, dirs. (1993): Nuevo Diccionario de Americanismos. Tomo III. Nuevo Diccionario de Uruguayismos, Bogotá, Instituto Caro y Cuervo. Con la colaboración de Úrsula Kühl de Mones.

HAENSCH, Günther y Reinhold WeRnER, dirs. (2000): Diccionario del español de Argentina. Español de Argentina / Español de España, Madrid, Gredos.

KANY, Charles (1976): Sintaxis hispanoamericana, Madrid, Gredos.

LARA, Luis Fernando (1976): El concepto de norma en lingüística, México, El Colegio de México.

LARA, Luis Fernando, dir. (1996): Diccionario del español usual en México, México, El Colegio de México.

NORMAS. REVISTA DE ESTUDIOS LINGÜÍSTICOS HISPÁNICOS, NÚMERO 1 (AÑO 2011):

https://www.uv.es/normas 
LARA, Luis Fernando et alii (2002): Diccionario del español usual en México, México, El Colegio de México.

LARA, Luis Fernando (2007): «Por una reconstrucción de la idea de la lengua española», en La lengua ¿patria común? Ideas e ideologías de la lengua española, 163-182, Madrid, Iberoamericana.

LARA, Luis Fernando, dir. (2010): Diccionario del español de México, México D. F., El Colegio de México.

LODARES, Juan Ramón (2001): Gente de Cervantes, Madrid, Taurus.

LODARES, Juan Ramón (2005): El porvenir del español, Madrid, Taurus.

LÓPEZ MORALES, Humberto (2003): «Diccionario académico de americanismos; síntesis de planta», en Martín Zorraquino, M. Antonia y José Luis Aliaga Jiménez, eds., Lexicografía hispánica ante el siglo XXI. Balance y perspectivas, 115-127, Zaragoza, Gobierno de Aragón-Institución Fernando el Católico.

LÓPEZ Morales, Humberto, (2010): La andadura del español por el mundo, Madrid, Taurus.

MARÍAS, Julián (2000): Ser español: ideas y creencias en el mundo hispánico, Barcelona, Planeta.

MEnÉndeZ PIDAL, Ramón (1944): La unidad del idioma, Madrid, Instituto Nacional del Libro Español.

Moliner, María (1998): Diccionario de uso del español, 2. ${ }^{\mathrm{a}}$ ed. [revisada y ampliada por la editorial], Madrid, Gredos.

Moliner, María (1966): Diccionario de uso del español, Madrid, Gredos.

MORAles PetTORINO, Félix (2006): Nuevo diccionario ejemplificado de chilenismo y de otros usos diferenciales del Español de Chile, Valparaíso, Puntángeles.

MORAles PETTORINO, Félix, dir. (1987): Diccionario ejemplificado de chilenismos y de otros usos diferenciales del español de Chile, Valparaíso, Academia Superior de Ciencias Pedagógicas de Valparaíso.

OrtúZAR, Camilo (1983): Diccionario manual de locuciones viciosas y de correcciones del lenguaje, con indicación del valor de algunas palabras y ciertas nociones gramaticales, s.1., S. Benigno Canavese-Imprenta Salesiana.

Plager, Federico (2008): Diccionario integral del español en la Argentina, Buenos Aires, Voz Activa.

Quesada Pacheco, Miguel Ángel (1993): Nuevo Diccionario de Costarriqueñismos, Editorial Tecnológica de Costa Rica.

REAL ACADEMIA ESPAÑola (1963 [1732-37]): Diccionario de autoridades, Madrid, Gredos. 
ReAl ACAdemia EsPañola (2001): Diccionario de la lengua española, 22. ed., Madrid, Espasa Calpe.

Real ACADEMIa EsPañola Y Asociación DE ACADEMias DE LA LENGUA ESPAÑOLA (2005): Diccionario panhispánico de dudas, Madrid, Santillana.

Rosenblat, Ángel (1962): El castellano de España y el castellano de América. Unidad y diferenciación. Cuadernos del Instituto de Filología Andrés Bello, Universidad Central de Venezuela, Caracas (Reproducido en: Rosenblat, Ángel: Nuestra lengua en ambos mundos, Barcelona, 1971).

Rosenblat, Ángel (1967): «El criterio de corrección lingüística: Unidad o pluralidad de normas en el castellano de España y América», en: El Simposio de Indiana, Bogotá, Instituto Caro y Cuervo, 3-36. la Plata.

RossI, Vicente (1929): Idioma nacional rioplatense (arjentino-uruguayo), Río de

SeCo, Manuel; Olimpia ANDRÉs y Gabino RAMos (1999): Diccionario del español actual, Madrid, Aguilar.

TEJERA, María Josefina, dir. (1983-1993): Diccionario de Venezolanismos, Caracas, Academia Venezolana de la Lengua y Universidad Central de Venezuela, tomo. I (1983), tomos II y III (1993).

TORRENT-LENZEN, Aina (2006): Unidad y pluricentrismo en la comunidad hispanohablante. Cultivo y mantenimiento de una norma panhispánica unificada,Titz, Axel Lenzen Verlag.

URIBE, Rafael (1887): Diccionario abreviado de galicismos, provincialismos y correcciones del lenguaje con trescientas notas explicativas, Medellín, Imprenta del Departamento.

VALLE, José del (2010): «La construcción del hispanismo trasatlántico: lecciones de una polémica mexicana sobre el idioma», en Julio Ortega, ed. Nuevos hispanismos interdisciplinarios y trasatlánticos, 227-238. Madrid, Iberoamericana.

VALLE, José del, ed. (2007): La lengua ¿patria común? Ideas e ideologías de la lengua española, Madrid, Iberoamericana.

ZimMERMANN, Klaus (2003): «El fin de los diccionarios de mexicanismos, colombianismos, argentinismos, cubanismos etc. La situación de la lexicografía del español de América después de la publicación de los Diccionarios contrastivos del español de América [...]». Revista Internacional de Lingüística Iberoamericana, 1 (1), 71-83. 
